\title{
Effect of Lifestyle based Edu Vaccine in Indian community: Study Outcomes of National Program for Prevention and Eradication of Heart Attack (NPPEHA)
}

\author{
Bimal Chhajer ${ }^{1}$, Vikram Singh ${ }^{2 *}$, Girija Kumari², Roheed Amin ${ }^{1}$, Sachin Tiwari ${ }^{1}$, Pawan Jaiswal ${ }^{1}$, Manish Kumar Gupta \\ ${ }^{1}$ SAAOL Heart Center, New Delhi, India. \\ ${ }^{2}$ Amity Medical School, Amity University, Gurugram, India.
}

\begin{tabular}{|c|c|}
\hline ARTICLE INFO & ABSTRACT \\
\hline Received on: 12/05/2019 & Objective: The present study was designed to evaluate the impact of Education (Edu) vaccine in National Program for \\
\hline Accepted on: 19/11/2019 & Prevention and Eradication of Heart Attack (NPPEHA). \\
\hline Available online: $03 / 01 / 2020$ & $\begin{array}{l}\text { Methods: This pretest-posttest designed study was held in the SAAOL Heart Center in different cities (Delhi, } \\
\text { Kolkata, Bangalore, and Mumbai) of India from Nov } 2016 \text { to Dec } 2017 \text {. Total 6,225 community people were enrolled. }\end{array}$ \\
\hline $\begin{array}{l}\text { Key words: } \\
\text { NPPEHA, } \\
\text { coronary artery disease, } \\
\text { heart attack, Edu vaccine, } \\
\text { SAAOL heart center. }\end{array}$ & $\begin{array}{l}\text { An educational counseling intervention (Edu vaccine) comprising: knowledge of heart, heart disease awareness, } \\
\text { risk factor awareness, preventive measure awareness and diagnostic, and regular medical checkups were given to } \\
\text { community people with expert doctors through face-to-face interactions and video counseling. The effect of lifestyle- } \\
\text { based counseling was assessed through pre- and post-designed Edu vaccine questionnaire. } \\
\text { Results: The results of this study showed a significant improvement in knowledge of heart }(79.6 \%) \text {, heart disease } \\
\text { awareness }(87.8 \%) \text {, risk factor awareness }(74.9 \%) \text {, preventive measure awareness }(89.8 \%) \text {, diagnostic, and regular } \\
\text { medical checkups }(84.7 \%) \text {, respectively. } \\
\text { Conclusion: The results of this study showed a significant improvement in knowledge of heart }(79.6 \%) \text {, heart disease } \\
\text { awareness ( } 87.8 \%) \text {, risk factor awareness ( } 74.9 \%) \text {, preventive measure awareness }(89.8 \%) \text {, diagnostic, and regular } \\
\text { medical checkups }(84.7 \%) \text {, respectively. The first phase study of NPPEHA results conclude that lifestyle-based Edu } \\
\text { vaccine is effective, and this tool is very easy to follow and heart attack prevention methods. The next phase of } \\
\text { NPPEHA program is ongoing and results are awaited. }\end{array}$ \\
\hline
\end{tabular}

\section{INTRODUCTION}

Coronary heart disease (CHD) is a non-infectious, fetal, lifestyle related disease, develops due to increasing age, unhealthy diet, obesity, physical inactivity, consumption of tobacco, higher intake of alcohol, and stress (Bijnen et al., 1994; Das et al., 2007). Coronary artery disease is a chronic inflammatory condition in which coronary artery wall become thickened due to the accumulation of fatty particles and lipoprotein deposition occurs. The further plaque formation may lead to heart attack (Tourlouki et al., 2009).

\section{"Corresponding Author}

Dr. Vikram Singh, Amity Medical School, Amity University, Gurugram, India.E-mail: vsmicroaiims@gmail.com
CHD is epidemic in India and the major cause of morbidity and mortality around the world. Currently, it is accounting for $21.9 \%$ of total deaths and projected to increase to $26.3 \%$ by 2030 (Hickox et al., 2016). The current prevalence of CHD is higher in urban areas (12.6\%) as compared to the rural areas (4.6\%), and it is continuously increasing (Gupta et al., 2016).

CHD is a very expensive disease due to its current invasive treatment methods, it consumes a significant portion of household's income because of its chronic nature, long duration of hospitalization, and treatment complications that further required expensive medicines (Ali et al., 2010; Srinivasan et al., 2017). Patient education about the disease, symptoms, risk factors, and treatment are essential components of patient care after getting heart disease has found cost effective and reduce surgery cost and duration of hospitalization (Castelein et al., 1995). 
Several studies indicated that a poor knowledge about the disease and its treatment and management is associated with a higher Body Mass Index (BMI), poor glycemic control, more complications and co-morbidities, more angina episodes, and prolonged use of pharmacological treatment (Khattab et al., 2010). Hence, repeated health education and lifestyle modifying interventions by physicians and other health educators are required (Habib et al., 2003).

The results of two randomized controlled trials showed a significant improvement in physiological and biochemical parameters in T2DM patients following a 6-month lifestyle intervention program (Adachi et al., 2013; Spencer et al., 2011). Cardiovascular risk factors are prevalent, however, they are not recognized due to a lack of knowledge and awareness of CHD and lack of appropriate screening (Mosca et al., 2011; Villablanca et al., 2010).

Two out of three people have at least one of the major risk factors for developing $\mathrm{CHD}$, such as high blood pressure, high cholesterol, diabetes mellitus, unbalanced diet, physical inactivity, stress, and obesity (Go et al., 2014). Thus, knowledge and awareness of heart disease risk factors are the key theme to help people and to adopt healthy lifestyles, encourage prevention of lifestyle related diseases, and reduce the rate of heart attacks.

According to Bastable et al. (2006), the main purpose of patient counseling or education is to increase the patient's ability, confidence and competence in self-care management, and the major goal is to prepare patients and family for independence (Bastable et al., 2006). Counseling is aimed at improving patient functional capacity and increasing health standard and increase patient understanding of their problem, resources, and limitation and also builds patient capacity (Ayers et al., 2007). A study has proven that counseling helps people in managing life problem by providing support, motivation, encouragement, hope, and comfort (Dev et al., 2005). Educated patients can develop skills that allow them to manage and control CHD and other related complications (Chhajer et al., 2018; Mustapha et al., 2014). Bower et al. (2006) did a systematic review and meta-analysis study to assess clinical effectiveness of counseling in primary care and his study conclude that counseling is effective and delivers some short-term outcomes with the satisfactions of the participants Bower et al. (2006). Another systematic review done by Lin et al. on the U.S. preventive services task force with special concern on behavioral counseling to prevent cardiovascular risk factors and associated disease conclude that behavioral counseling is effective for the management of cardiovascular disease and its risk factors. The effective results of the counseling may sustain for the years (Lin et al., 2014). Hence, lifestyle counseling or Edu vaccine generally used as an intervention is a novel, cost-effective, non-invasive method to prevent and control CHD, and decrease premature death due to lack of awareness about the disease.

Here, we developed a National Program for Prevention and Eradication of Heart Attack for improving cardiac health of Indian population and reduces the national burden in terms of NonCommunicable Diseases. National Program for Prevention and Eradication of Heart Attack (NPPEHA) is an awareness program, for increasing awareness about lifestyle management or Edu vaccine. In this program, community peoples were educated about heart, heart attacks and its prevention and control in a natural way.
This program aims to educate millions of people across the India involves free medical camps to check the biochemical assessment-lipid and sugar profile: physiological-blood pressure, pulse, and to educate people for prevention and eradication of heart attack. The purpose of this study was to assess the effect of lifestyle Edu vaccine provided by Educational video and face-toface interaction - a tool used for counseling to community people to eradicate heart attack.

\section{MATERIALS AND METHODS}

\section{Study design and setting}

This pretest and posttest designed study was conducted in the SAAOL Heart Center in different cities (Delhi, Kolkata, Bangalore, and Mumbai) of India from Nov 2016 to December 2017. In this study, community people were enrolled based on consecutive sampling technique. This study was conducted in two phases.

The planning and preparation for counseling components [Heart Education, Heart Attack Awareness, Knowledge of Cardiac Risk Factors, Heart disease co-morbidity awareness and prevention, Zero oil diet, Fruit and vegetable (Fibrous diet), Physical activity, Stress management and proper sleep, Yoga and meditation], and recruitment of participants was done in the first phase. Implementation of counseling, data collection, and data analyses was done in the second phase.

\section{Eligibility criteria}

Community people of age more than 18 years, willing to participate and able to give valid written informed consent were included in this study. Community persons under age of 18 years, hospitalized, having mental disorder, visual, hearing problems and unwilling to participate were excluded from the study.

\section{Sample size}

Total 6,225 subjects were recruited as they fulfilled the study eligibility criteria from the SAAOL Heart Centers of different cities (Delhi, Kolkata, Bangalore, and Mumbai) based on consecutive sampling technique. The total duration of this study was 1 year (Nov 2016-Dec 2017). The minimum calculated sample size for this study was 4,147 with a margin of error $5 \%$ and confidence of the interval of $95 \%$.

Sample size for the proposed study was calculated by using a standard formula:

$$
N=\frac{Z^{2} p(1-p)}{e^{2}}
$$

In this formula, $Z$ is the corresponding confidence interval, $e$ is the margin of error, and $p$ is the estimated value of the proportion of samples having the condition of interest. The overview of study with Screening, Enrollment, Intervention, and Analysis is given in Table 1.

\section{Intervention}

Lifestyle-based counseling was used as an intervention tool for participants who were participating in the NPPEHA program to prevent and control Heart Attacks. Lifestyle-based Edu vaccine is a combined package of knowledge and education, provided by clinical experts through videos and pictures to educate 
Table 1. Overview of study with screening, enrollment, intervention, and analysis.

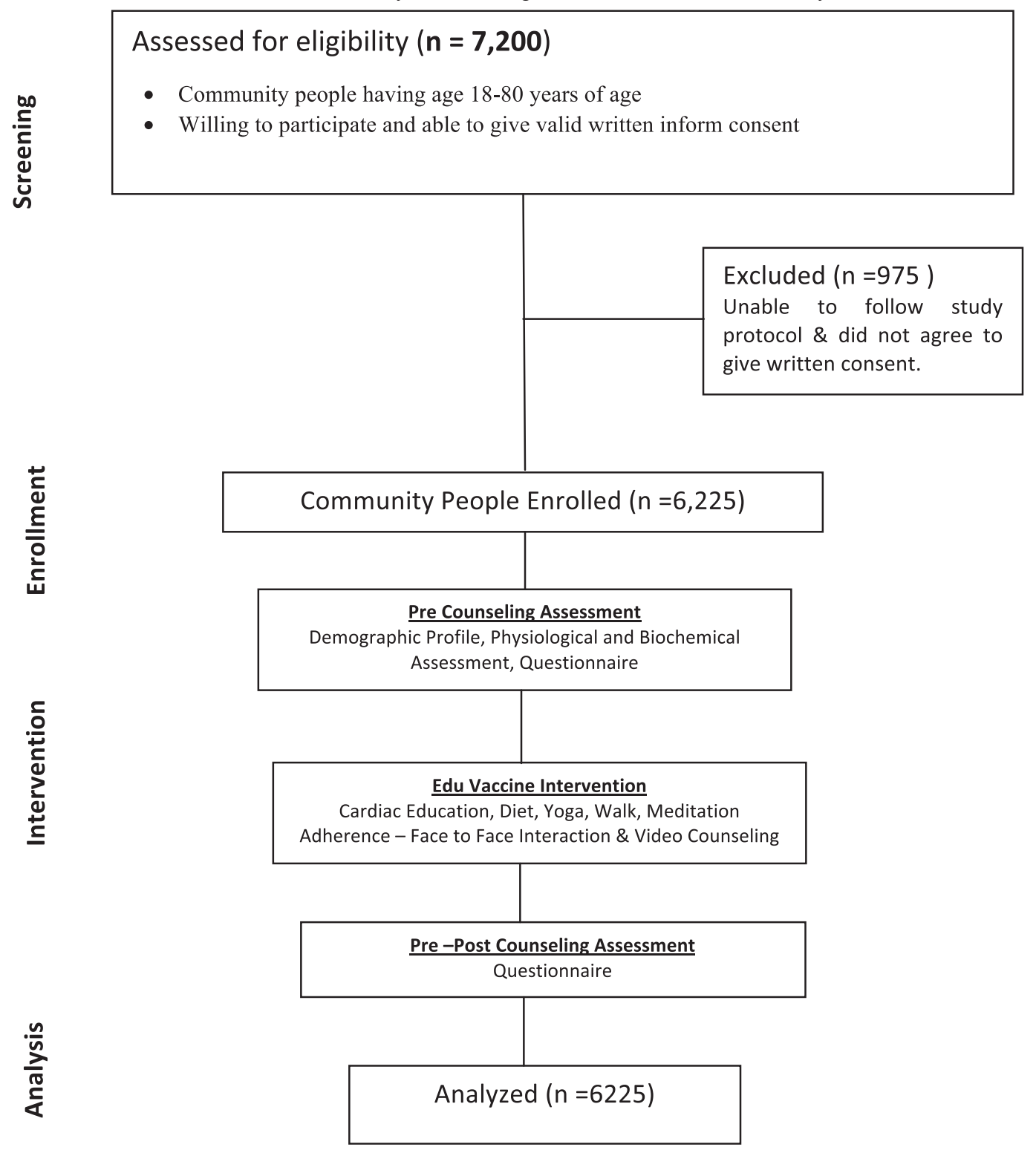

community people even an illiterate person in a very simple way about heart, human body, risk factors leads to heart attack, warning signs, and how to eradicate a heart attack through awareness of diet, yoga, walking, meditation, and regular medical checkups.

The lifestyle management sessions were provided by an experienced dietitian, health education, physical trainer, and heart and lifestyle experts. All lifestyle management counseling components were explained in the local language, supported by pictures and video by a group of individuals.

Lifestyle-based Edu vaccine contains 10 essential components for counseling, including-Heart Education, Heart Attack Awareness, Knowledge of Cardiac Risk Factors, Heart disease co-morbidity awareness and prevention, Zero oil diet, Fruit, and vegetable (Fibrous diet), Physical activity, Stress management and proper sleep, Yoga and meditation. Each session of lifestyle modification counseling took 38 minutes video and face-to-face doctor consultation.

\section{Measurements}

Demographic profile (age, sex, locality, medical history, and education) of communities' people was taken at the beginning of the study. After that, the anthropometric (Height, weight, and BMI), physiological (Blood pressure and pulse rate), and Biochemical [Blood sugar fasting, Postprandial (PP), and lipid profile] measurements of all study participants were done before intervention. Height and weight of all study participants were measured using a "Stadiometer" and "SECA" digital scale, and BMI was calculated by using a formula of weight in $\mathrm{kg}$ divided by height in $\mathrm{m}^{2}\left(\mathrm{~kg} / \mathrm{m}^{2}\right)$.

Systolic and Diastolic Blood pressure of the study participants was recorded by trained personnel, using an automatic digital blood pressure monitor of Diamond Company (Diamond clock model B.P monitor). Pulse was measured using a ChoiceMMed MD300C2D pulse oximeter. Blood Sugar Fasting and PP tests were analyzed using Glucose oxidase (GOD) and Peroxidase (POD) 
method, Lipid Profile consists cholesterol by the Cholesterol oxidase- Phenol 4-aminoantipyrine peroxidase method, triglyceride by Glycerol-3-phosphate oxidase method, high-density lipoproteins (HDL)-cholesterol by immune inhibition method was done and low density lipoproteins (LDL) was calculated using a standard formula $[\mathrm{LDL}=$ Total Cholesterol $-\mathrm{HDL}-($ Triglycerides / 5) $]$. After that, cardiac awareness of study participants was assessed with the help of the Cardiac Awareness Questionnaire. This Questionnaire contains total 20 basic questions about heart, heart attack, sign, symptoms, and risk factors for heart disease, normal values of body parameters, medication, and prevention methods of heart attack, etc. Then lifestyle intervention counseling or Edu vaccine was provided by clinical experts (dietician, health education, physical trainer, and heart and lifestyle experts) with the help of pictures and videos.

After lifestyle intervention counseling, the Cardiac Awareness Questionnaire was again provided to the study participants to assess the improvement in cardiac awareness and knowledge after intervention.

\section{Statistical analysis}

Statistical package for the social sciences software version 21 was used for all statistical analyses. In this study, percentage, mean, standard deviation (SD), median, and sample paired $t$-test was used in the assessment of study parameters.

\section{Ethical approval and consent}

Ethical approval of the present study was granted by SAAOL Heart Center ethics committee with Ref No. Saaol/ NPPEHA/Ethics/02/2015. Before initiation of the study, the informed consent was obtained from all the enrolled study participants.

\section{RESULTS}

\section{Baseline assessment of total 6,225 participants}

In the present study, the data of 6,225 participants were analyzed. The mean (SD) age of the total study participants was $56.42 \pm 16.78$ with an age range from 18 to 80 . The number of female participants was higher than male's participants.

The average range of total cholesterol was 169.50 and the triglyceride level was 147.46 at baseline. The mean (SD) of good cholesterol, i.e., HDL was $53.27 \pm 15.341$ at baseline. The mean (SD) of blood sugar fasting was $103.673 \pm 33.6055$ and blood sugar PP was $146.25 \pm 41.216$ at initial. The mean (SD) of weight and height was $65.52 \pm 13.113$ and $5.2571 \pm 0.377$ and BMI was $24.57 \pm 4.98$. The average mean of systolic blood pressure was 82.77 and diastolic blood pressure mean was 131.25. The average pulse rate of study participants was 66.28 at baseline assessment. The detail of baseline assessment profile of total study participants is given in Table 2 .

\section{Baseline assessment of Bangalore participants}

Out of 6,225 participants, 1,469 were belonging to Bangalore. The mean (SD) age of the study participants was 56.38 \pm 16.77 . The number of female participants was higher than male's participants in Bangalore. The average range of total cholesterol was 159.09 and the triglyceride level was 147.35 at baseline.

The mean (SD) of HDL was $49.98 \pm 9.061$ at baseline. The mean (SD) of blood sugar fasting was $93.716 \pm 23.8437$ and blood sugar PP was $149.85 \pm 43.065$ at initial. The mean (SD) of weight and height was $65.52 \pm 12.797$ and $5.29 \pm 0.366$ and BMI was $23.47 \pm 3.68$. The average systolic blood pressure was 81.49 , while diastolic blood pressure 130.07 and average pulse rate was 66.05 at baseline assessment. The detail of baseline assessment of Bangalore participants is given in Table 3 .

\section{Baseline assessment of Delhi participants}

Out of 6,225 participants, 1,655 participants were attended counseling program in Delhi. The mean (SD) age of the Delhi participants was $56.49 \pm 16.784$. The number of female participants was higher than male's participants in Bangalore. The average range of total cholesterol was higher 174.30 as compared to other cities and the triglyceride level was also higher 154.06 at baseline. The mean (SD) of HDL was $47.76 \pm 8.719$ at baseline. The mean (SD) of blood sugar fasting was lower as compared to other cities $96.31 \pm 22.050$ and blood sugar PP was 140.28 \pm 39.968 at initial. The mean (SD) of weight and height was 65.95 \pm 13.468 and $5.236 \pm 0.38$ and BMI was $22.85 \pm 3.80$.

The average systolic blood pressure was 83.48 , while diastolic blood pressure 132.09 and average pulse rate was 66.23 at baseline assessment. The detail of baseline assessment of Delhi participants is given in Table 4.

\section{Baseline assessment of total Kolkata participants}

Out of 6,225 participants, 1,634 were participating in the Kolkata counseling program in. The mean (SD) age of the Kolkata study participants was $56.42 \pm 16.8$. The number of female

Table 2. Baseline assessment profile of total study participants.

\begin{tabular}{lcccc}
\hline Variables & Mean & SD & Chi-square & $p$-value \\
\hline Age & 56.42 & 16.78 & & \\
Cholesterol & 169.5 & 45.11 & & \\
Triglyceride & 147.46 & 47.64 & & \\
HDL & 53.27 & 15.34 & & \\
Blood sugar F & 103.673 & 33.60 & & \\
Blood Sugar PP & 146.25 & 41.21 & 139.4 & 0.082 \\
BMI & 24.57 & 4.98 & & \\
BP systolic & 82.77 & 11.98 & & \\
BP Diastolic & 131.25 & 19.50 & & \\
Pulse & 66.28 & 10.56 & & \\
\hline
\end{tabular}

Table 3. Baseline assessment of Bangalore participants.

\begin{tabular}{lcccc}
\hline Variables & Mean & SD & Chi-square & $p$-value \\
\hline Age & 56.39 & 16.77 & & \\
Cholesterol & 159.09 & 50.24 & & \\
Triglyceride & 147.35 & 41.10 & & \\
HDL & 49.98 & 9.06 & & 0.094 \\
Blood sugar F & 93.716 & 23.84 & & \\
Blood sugar PP & 149.85 & 43.06 & & \\
BMI & 23.47 & 3.68 & & \\
BP systolic & 81.49 & 9.83 & & \\
BP diastolic & 130.07 & 19.06 & & \\
Pulse & 66.05 & 10.44 & & \\
\hline
\end{tabular}


participants was higher than male's participants in Bangalore. The average range of total cholesterol was 179.68 which was higher and the triglyceride level was 139.16 at baseline. The mean (SD) of HDL was $50.91 \pm 10.264$ at baseline. The mean (SD) of blood sugar fasting was $96.74 \pm 19.514$ and blood sugar PP was $148.93 \pm 41.823$ at initial. The mean (SD) of weight and height was $65.74 \pm 13.343$ and 5.272 \pm 0.37 and BMI was $23.87 \pm 4.15$. The average systolic blood pressure was 82.06 , while diastolic blood pressure 129.07 and the average pulse rate was 66.23 at baseline assessment. The detail of baseline assessment of Kolkata participants is given in Table 5 .

\section{Baseline assessment of total Mumbai participants}

Out of 6,225 participants, 1,447 were belonging to Mumbai. The mean (SD) age of the Mumbai study participants was $56.38 \pm 16.8$. The number of female participants was higher than male's participants in Bangalore. The average range of total cholesterol was 164.36 and the triglyceride level was 148.58 at baseline. The mean (SD) of HDL was $51.85 \pm 9.877$ at baseline. The mean (SD) of blood sugar fasting was $122.02 \pm 46.423$ and blood sugar PP was $144.75 \pm 39.297$ at initial. The mean (SD) of weight and height was $65.65 \pm 12.742$ and $5.229 \pm 0.38$ and BMI was $26.89 \pm 5.87$. The average systolic blood pressure was 83.51 , while diastolic blood pressure 133.91 and average pulse rate was 66.25 at baseline assessment. The detail of baseline assessment of Mumbai participants is given in Table 6.

Table 4. Baseline assessment of Delhi participants.

\begin{tabular}{lcccc}
\hline Variables & Mean & SD & Chi-square & $p$-value \\
\hline Age & 56.49 & 16.78 & & \\
Cholesterol & 174.3 & 44.29 & & \\
Triglyceride & 154.06 & 56.36 & & \\
HDL & 47.76 & 8.71 & & 0.047 \\
Blood sugar F & 96.31 & 22.05 & & \\
Blood sugar PP & 140.28 & 39.96 & & \\
BMI & 22.85 & 3.80 & & \\
BP systolic & 83.48 & 13.41 & & \\
BP diastolic & 132.09 & 20.30 & & \\
Pulse & 66.23 & 10.54 & & \\
\hline
\end{tabular}

Table 5. Baseline assessment of total Kolkata participants.

\begin{tabular}{lcccc}
\hline Variables & Mean & SD & Chi-square & $p$-value \\
\hline Age & 56.42 & 16.77 & & \\
Cholesterol & 179.68 & 41.08 & & \\
Triglyceride & 139.16 & 37.29 & & \\
HDL & 50.91 & 10.26 & & 0.074 \\
Blood sugar F & 96.74 & 19.51 & & \\
Blood sugar PP & 148.93 & 41.82 & 150.3 & \\
BMI & 23.87 & 4.15 & & \\
BP systolic & 82.06 & 8.95 & & \\
BP diastolic & 129.07 & 18.68 & & \\
Pulse & 66.23 & 10.56 & & \\
\hline
\end{tabular}

Summary of lifestyle-based counseling effectiveness on all study participants

Effect of lifestyle counseling or Edu vaccine was assessed through Cardiac Awareness Questionnaire and found a significant improvement in patient knowledge about heart disease, heart, human body, warning signs, risk factors lead heart attack, and how to eradicate a heart attack through, diet, yoga, walking, meditation, and regular medical checkups after Edu vaccine intervention was compared with pre assessment to post assessment.

Five essential components were: Knowledge of Heart, Heart Disease Awareness, Risk Factor Awareness, Preventive Measure Awareness and Diagnostic, and Regular Medical Checkups. The knowledge of Heart pre-assessment percentage of study participants was 26.8 at baseline, but this percentage was significantly increased after intervention about $79.6 \%$. Heart Disease Awareness pre assessment percentage of study participants was 21.4 but after intervention at post assessment it increased about $87.8 \%$.

Risk Factor Awareness of study participants in pre assessment was 15.7 percentages, but after the intervention of Edu vaccine, it was increased about $74.9 \%$ of post assessment. Preventive Measure Awareness percentage of study participants was 13.9 was very low at pre assessment, but it was significantly improved (89.8\%) after intervention at post assessment, similarly the diagnostic and regular medical checkups awareness percentage of study participants were very low $(9.7 \%)$ at pre assessment, and it was significantly increased after receiving Edu vaccine and became about $84.7 \%$ after intervention in post assessment. Lifestyle-based counseling effectiveness summary results of all the participants are given in Table 7.

\section{DISCUSSION}

In the present study, lifestyle-based Edu vaccine showed a significant improvement in patient knowledge about heart disease, heart, human body, warning signs, risk factors lead heart attack, and how to eradicate a heart attack through, diet, yoga, walking, meditation, and regular medical checkups after Edu vaccine intervention as compared to baseline or pre assessment. In the present study, education about risk factors, such as smoking, lack of exercise, and inadequate diet and ways of modifying lifestyle, was effective and improve the awareness of patient after getting an education as compared to before. Our study concludes

Table 6. Baseline assessment of total Mumbai participants.

\begin{tabular}{lcccc}
\hline Variables & Mean & Std. deviation & Chi-square & $p$-value \\
\hline Age & 56.38 & 16.80 & & \\
Cholesterol & 164.36 & 42.25 & & \\
Triglyceride & 148.58 & 51.34 & & \\
HDL & 51.85 & 9.87 & & 0.069 \\
Blood sugar F & 122.02 & 46.42 & & \\
Blood sugar PP & 144.75 & 39.29 & & \\
BMI & 26.89 & 5.87 & & \\
BP systolic & 83.51 & 13.52 & & \\
BP diastolic & 133.91 & 19.51 & & \\
Pulse & 66.25 & 10.57 & & \\
\hline
\end{tabular}


Table 7. Summary of Edu vaccine (lifestyle based counseling) effectiveness on all participants.

\begin{tabular}{lccc}
\hline Intervention Variables & $\begin{array}{c}\text { Pre-assessment } \\
\text { (\%) }\end{array}$ & $\begin{array}{c}\text { Post-assessment } \\
\text { (\%) }\end{array}$ & p-value \\
\hline 1. Knowledge of heart & 26.8 & 79.6 & \\
• Basics of heart & 10.0 & 26.1 & \\
- Shape \& size & 6.2 & 18.0 & $<0.0001$ \\
- Functions & 4.4 & 15.1 & \\
- Coronary arteries & 6.2 & 20.4 & \\
2. Heart disease awareness & 21.4 & 87.8 & \\
- Sign \& symptoms & 9.2 & 32.2 & \\
- Angina (chest pain) & 6.0 & 21.1 & $<0.0001$ \\
- Blockage & 2.2 & 16.2 & \\
- Heart attack & 4.0 & 18.3 & \\
3. Risk factor awareness & 15.7 & 74.9 & \\
- Physical inactivity & 7.3 & 22.2 & \\
- Diet & 4.2 & 16.3 & $<0.0001$ \\
- Stress & 2.3 & 17.3 & \\
- Obesity, diabetes, hypertension & 1.9 & 19.1 & \\
4. Preventive measure awareness & 13.9 & 89.8 & \\
- Plant based diet & 1.4 & 30.2 & \\
- Walking & 7.2 & 19.2 & $<0.0001$ \\
- Yoga & 3.2 & 18.1 & \\
- Meditation & 2.1 & 22.3 & \\
5. Diagnostic \& regular medical checkups & 9.7 & 84.7 & \\
- Test for risk factor assessment & 2.1 & 27.2 & \\
- Lipid profile tests & 4.3 & 17.0 & $<0.0001$ \\
- Test for blockages & 2.1 & 15.3 & \\
- Test for pumping & 1.2 & 25.2 & \\
\hline
\end{tabular}

that the lifestyle-based counseling on the following parameters: Knowledge of Heart, Heart Disease Awareness, Risk Factor Awareness, Preventive Measure Awareness, and Diagnostic \& Regular Medical Checkups was effective and significantly increase the awareness of participants and this knowledge about the disease and lifestyle management will help them to change their lifestyle and reduce the risk of heart attacks and other lifestyle disorders.

A study done by Shahamfar et al. (2007) concluded that the education about the disease and its risk factor awareness can reduce the prevalence and burden of disease. These findings are similar to the result of Shea et al. (1991) study. In his study, after education the risk factors and overcome of disease in the experimental group was significantly improved.

Another study done by Lindsay reveals that lifestyle modification with increasing the knowledge of the heart and heart disease can significantly reduce the risk factors of disease (Lindsay et al., 1991). A study done by Castelein et al. (1995) reveals that the Patient education is a key component of cardiac patient care and found to be cost effective in terms of to reduce disease recurrence, complications and the length of hospitalization.

A study by Scalzi et al. (1980) findings conclude that intervention (education) teaching sessions achieved a reduction in cigarette consumption and improve in other risk factors for coronary disease. A study conducted by Ornish et al. (1998) to assess the effect of dietary changes and stress management education, he found a significant improvement HDL cholesterol and a reduction in total serum cholesterol and triglyceride in the experimental group.

Clinical trial study conducted by Campbell et al. (1998) in Scotland have shown that a health education program conducted by nurses has a positive impact on cardiac risk factors and reduction in patients with CHD. An observational study done by Baillargeon et al. (2001) in Canada found the cardiac health education program conducted by nurses can reduce the risk factor of heart disease and increase the awareness of disease management as well as reduce the number of CHD patients.

The results of Yavarikia et al. (2011) study also support the present study and showed a reduction in risk factors decreased the probability of sudden death and hospitalization rate in CHD patients after health education in patients (Yavarikia et al. 2011). A study by Bastable et al. (2006) concluded that the educational counseling about the disease can increase patient satisfaction, quality of life, coping skills, and improve ability to manage chronic nature of heart failure. According to Richard et al. (2011), counseling can lead to reduced health care cost, patient anxiety, reduces complications of illness, promote independence in the performance of activities of daily living and improve adherence to treatment plan.

A study carried out by Otsu et al. (2011) based on educational counseling on medication, physical activity, saltrestricted diet, smoking and drinking cessation have shown an increase in medication compliance, increase physical activity compliance, salt-restricted diet compliance and improve patient's quality of life over a period of 6-month counseling.

Due to increasing adherence, a significant improvement was observed in symptoms and risk factor management and enhance patient quality of life (Otsu et al., 2011). These all abovementioned studies support the present study and confirm that the lifestyle intervention based counseling may significantly improve the patient's knowledge and awareness about heart disease, risk factors, treatment and management regiments which may help in the improvement in health outcomes and reduce the burden of disease and the prevalence of heart attacks.

\section{CONCLUSION}

The present study showed a positive effect of lifestylebased Edu vaccine in community people and found a significant improvement in the participants' knowledge about heart disease, sign, risk factors, and eradication of heart attack through; diet, yoga, walking, meditation, and regular medical checkups. NPPEHA first phase study outcomes are effective and the second phase is going on.

\section{ACKNOWLEDGMENTS}

The authors are highly grateful to the Emami Foundation to provide financial assistance to complete the free health checkup camps and help in this study. We are also thankful to health professionals of SAAOL Heart Centers and other organizations to complete this study.

\section{CONFLICT OF INTEREST}

The authors declare that they do not have any conflicts of interest. 


\section{REFERENCES}

Adachi M, Yamaoka K, Watanabe M, Nishikawa M, Kobayashi I, Hida E, Tango T. Effects of lifestyle education program for type 2 diabetes patients in clinics: a cluster randomized controlled trial. BMC Public Health, 2013; 13(1):467.

Ali MK, K.M. Venkat Narayan KM, Tandon N. Diabetes and coronary heart disease: Current perspectives. Indian J Med Res, 2010; 132: 584-97.

Ayers S, Baum A, McManus C, Newman S, Wallston K, Weinman J, West R. Cambridge handbook of psychology, health and medicine. Cambridge University Press, Cambridge, UK, 2008.

Baillargeon JP, Lepage S, Larrivée L, Roy MA, Landry S, Maheux P. Intensive surveillance and treatment of dyslipidemia in the postinfarct patient: evaluation of a nurse-oriented management approach. Can J Cardiol, 2001; 17:169-75.

Bastable SB. Essentials of patient education. (Online-book). Jones \& Bartlett Learning, Mount Ivy, New York, 2006.

Bijnen FC, Caspersen CJ, Mosterd WL. Physical inactivity as a risk factor for coronary heart disease: a WHO and International Society and Federation of Cardiology position statement. Bull World Health Organ, 1994; 72(1):1-4.

Bower PJ, Rowland N. Effectiveness and cost effectiveness of counselling in primary care. Cochrane Database Syst Rev, 2006; (3):CD001025; doi:10.1002/14651858.CD001025.pub2

Campbell NC, Ritchie LD, Thain J, Deans HG, Rawles JM, Squair JL. Secondary prevention in coronary heart disease: a randomised trial of nurse led clinics in primary care. Heart, 1998; (80):447-52.

Castelein P, Kerr JR. Satisfaction and cardiac lifestyle. J Adv Nurs, 1995; 21:498-505.

Chhajer B, Singh V, Kumari G, Lohmor M. Effect of yoga based lifestyle intervention on coronary artery disease Patients. Biomed Pharmacol J, 2018; 11(3).

Das UN. Obesity and its relationship to coronary heart disease. Eur Heart J, 2007; 28(23):2953-4.

Dev K. Educational counseling. (E-book). Pragun Publications, New Delhi, India, 2005. Available in the E-library database.

Go AS, Mozaffarian D, Roger VL, Benjamin EJ, Berry JD, Blaha MJ, Dai S, Ford ES, Fox CS, Franco S, Fullerton HJ, Gillespie C, Hailpern SM, Heit JA, Howard VJ, Huffman MD, Judd SE, Kissela BM, Kittner SJ, Lackland DT, Lichtman JH, Lisabeth LD, Mackey RH, Magid DJ, Marcus GM, Marelli A, Matchar DB, McGuire DK, Mohler ER 3rd, Moy CS, Mussolino ME, Neumar RW, Nichol G, Pandey DK, Paynter NP, Reeves MJ, Sorlie PD, Stein J, Towfighi A, Turan TN, Virani SS, Wong ND, Woo D, Turner MB. Heart disease and stroke statistics : a report from the American Heart Association. Circulation, 2014; 129:228-92.

Gupta R, Mohan I, Narula J. Trends in coronary heart disease epidemiology in India. Ann Glob Health, 2016 ; 82(2):307-24.

Hickox BC, Mikshowsky JA. Spontaneous coronary artery dissection: recognition, triage, and management in the emergency department. J Emerg Nurs, 2016; 42(4):301-5.

Khattab M1, Khader YS, Al-Khawaldeh A, Ajlouni K. Factors associated with poor glycemic control among patients with type 2 diabetes. J Diabetes Complications, 2010; 24:84-9.

Lin JS, O'Connor E, Evans CV, Senger CA, Rowland MG, Groom HC. Behavioral counseling to promote a healthy lifestyle in persons with cardiovascular risk factors: a systematic review for the U.S. Preventive Services Task Force. Ann Intern Med, 2014; 161:568-78; doi:10.7326/ M14-0130
Lindsay C, Jennrich JA, Biemolt M. Programmed instruction booklet for cardiac rehabilitation teaching. Heart Lung, 1991; 20:648-53.

Mosca L, Benjamin EJ, Berra K, Bezanson JL, Dolor RJ, LloydJones DM, Newby LK, Piña IL, Roger VL, Shaw LJ, Zhao D, Beckie TM, Bushnell C, D'Armiento J, Kris-Etherton PM, Fang J, Ganiats TG, Gomes AS, Gracia CR, Haan CK, Jackson EA, Judelson DR, Kelepouris E, Lavie CJ, Moore A, Nussmeier NA, Ofili E, Oparil S, Ouyang P, Pinn VW, Sherif K, Smith SC Jr, Sopko G, Chandra-Strobos N, Urbina EM, Vaccarino V, Wenger NK. Effectiveness-based guidelines for the prevention of cardiovascular disease in women, J Am Coll Cardiol, 2011; 57:1404-23.

Mustapha W, Hossain ZS, Loughlin KO. Management and impact of diabetes on quality of life among the lebanese community of Sydney: a quantitative study. J Diabetes Metab, 2014; 5(1):1-10.

Ornish D, Scherwitz LW, Billings JH, Gould KL, Merritt TA, Sparler S, Armstrong WT, Ports TA, Kirkeeide RL, Hogeboom C, Brand RJ. Long term lifestyle changes increase regression of coronary heart disease. Doctor`s Guide. JAMA, 1998;280:2001-7.

Otsu H, Moriyama M. Effectiveness of an educational selfmanagement program for outpatients with chronic heart failure. J Nurs Sci, $2011 ; 8(2): 140-52$.

Richard DM, Barbara AL. Patient education: a practical approach. USA Jones \& Bartlett Publishers, Wichita, Kansas, 2011.

Scalzi CC, Burke LE, Greenland S. Evaluation of an inpatient educational program for coronary patients and families. Heart Lung, 1980; 9:846- J Int Med Sci Acad, 2007; 20:257-8.

Shea S, Stein AD, Basch CE, Lantigua R, Maylahn C, Strogatz DS, Novick L. Independent associations of educational attainment and ethnicity with behavioral risk factors for cardiovascular disease. Am J Epidemiol, 1991; 134:567-82.

Spencer MS, Rosland AM, Kieffer EC, Sinco BR, Valerio M, Palmisano G, Anderson M, Guzman JR, Heisler M. Effectiveness of a community health worker intervention among African American and Latino adults with type 2 diabetes: a randomized controlled trial. Am J Public Health, 2011; 101(12):2253-60.

Srinivasan M, Bhat N, Kamath P, Pai N, Manjrekar P, Narasimhan $\mathrm{B}$, Mahabala C. Risk factors for complex and severe coronary artery disease in type 2 diabetes mellitus. J Cardiovasc Dis Res, 2017; 8(1):19-23.

Tourlouki E, Matalas A, Panagiotakos DB. Dietary habits and cardiovascular disease risk in middle-aged and elderly populations: a review of evidence. Clin Interv Aging, 2009; 4:319-30.

Villablanca AC, Beckett LA, Li Y, Leatherwood S, Gill SK, Giardina EG, Taylor AL, Barron C, Foody JM, Haynes S, D'Onofrio G. Outcomes of comprehensive heart care programs in high-risk women. J Womens Health (Larchmt), 2010; 19:1313-25.

Yavarikia M, Shahamfar J, Amidfar H. Assessment of the role of education in changing lifestyle in patients with coronary heart diseases. J Cardiovasc Thorac Res, 2011; 3(2):63-6.

How to cite this article:

Chhajer B, Singh V, Kumari G, Amin R, Tiwari S, Jaiswal P, Gupta MK. Effect of Lifestyle based Edu Vaccine in Indian community: Study Outcomes of National Program for Prevention and Eradication of Heart Attack (NPPEHA). J Appl Pharm Sci, 2020; 10(1):055-061. 